\title{
Implementation of Information and Communication Technology for Human Rights Awareness and Promotion
}

\author{
Gajendra Sharma ${ }^{a^{*}}$ \\ ${ }^{a}$ Department of Computer Science and Engineering, School of Engineering, Kathmandu University, Dhulikhel, Kavre, Nepal.
}

Received 06 January 2020; Revised 24 February 2020; Accepted 27 February 2020; Published 01 March 2020

\begin{abstract}
Information Technologies (ITs) are highly useful for human rights promotion globally. Information and Communication Technologies (ICTs) have proved an influential tool in the fight against violations of human rights. ICT has long represented a way to strengthen human rights. Technology also means that individuals' human rights are exposed to unprecedented risks, caused by the transition of these rights to the digital field. If we observe the different revolutions around the world, especially in countries that have had autocracy for a long period of time, they have been overruled with the help of ICTs. An analysis of the role of ICTs in human rights has been conducted. According to the study, Information and Communication Technology (ICT) play a critical role in raising awareness of and preventing violations of human rights for global citizens.
\end{abstract}

Keywords: Information Technology; Human Rights; Internet, ICT.

\section{Introduction}

Information and Communications Technology (ICT) includes any communication device or application. Advancement and technology development have facilitated electronic technologies for information processing and communication, as well as platforms. Recent technology developments have changed the method of information collection, storage, processing, dissemination, and use, thereby making it a powerful tool for transformation and development. ICT has been verified as one of the rapidly increasing areas that has the potential to promote a globalized economy [1]. Information is a source that activates the economy, making it possible for people to participate in government activities through public forums and contribute to the decision-making process [2]. ICTs are an effective tool if used responsively and with commitment to human rights in the perspective of Nepal and other parts of the country worldwide.

The same rights that citizens have offline should also be protected online [3]. As humanity experiences change online, so it follows in human rights. Emerging technologies have found their platform in modern society and are constantly being implemented by people to conduct their activities. Human rights are based on the principle of reverence for the individual. Their basic concept is that each person is an ethical and coherent being who deserves to be treated with self-esteem. They are called human rights as they are universal. So far, many people, when asked to list their rights, will name only freedom of speech and belief and one or two others. There is no question these are important rights, but the full scope of human rights is wide. They mostly include choice and opportunity. There were

* Corresponding author: gajendra.sharma@ku.edu.np

\section{doi http://dx.doi.org/10.28991/HIJ-2020-01-01-05}

$>$ This is an open access article under the CC-BY license (https://creativecommons.org/licenses/by/4.0/).

(C) Authors retain all copyrights. 
no human rights in an earlier period of time. After that, the idea emerged that people should have certain freedoms. Moreover, that idea, during World War II, resulted in the document called the Universal Declaration of Human Rights and the thirty rights to which all people are included.

The Human Rights Challenges and the Challenges of Implementation established by the United Nations' Report of 26 May 2005 are:

1. Poverty and global inequities

2. Discrimination

3. Armed conflict and violence

4. Impunity

5. Democracy deficits

6. Weak institutions.

The Challenges of Implementation are:

1. Knowledge gap

2. Capacity gap

3. Commitment gap

4. Security gap

As the information has become source for market and economy, it is also becoming an effective tool for Human rights for creating awareness, promotion and to fight against violation of Human rights. The basic concern is due to socialization and tyrannical culture as well as lack of knowledge about Human rights around the world. Human sense and education is very important for Human rights. Many multi-national companies and foundations are highly investing in start-ups, human rights groups and social organizations to construct, test and organize new or adapted technologies to understand human rights. Information Technologies such as artificial intelligence, big data analytics, and large-scale automation are determining our future. These technologies bring with them new and previously unexpected human rights risks as diverse as non-discrimination, privacy, child rights, freedom of expression, access to public services, and the right to work [4]. The analysis of a current legal problem in the area of the intersection of human rights and development of technology is highly important [5].

This paper aims to contribute to the argument on the transformations that the use of ICTs is intended to determine from a Human rights perspective. The contribution considers the undecided behaviour of emerging technologies as a primary point to properly understand the challenges they are having in the implementation of Human rights.

\section{Evolution of Human Rights}

Traditional human right in the context of the latest developments in the technical-scientific sector is a vital step for the protection of individuals' dignity in the digital era. Law is considered to rediscover its most authentic and essential quality being a means for ensuring social enhancement. Rules and regulations originate from society and follow their constant development in perfect bond and stability due to their flexible nature. Reality is not a static unit, but identifies an innovative evolution being in endless motion. So the purpose of the law is to observe all the changes and to adjust them to the new situation generated every time [6]. The digitalization of communication systems and their transition online is a result of innovation and awareness for society which is highly beneficial.

Bertot et al. (2010) [7] have identified that a first positive effect might be represented by the facilitation of transparency and the formation of effective law against corruption. But a major interest lies in ICT as a means to expose human rights violations in the society. ICTs build communication bridges among people and strengthen interaction, providing the exchange of ideas and points of view and contributing to the progress and prosperity of the society.

The huge potential and benefits of the ICT are created in its distinctive characteristics, such as promptness and global range, these features that facilitate people to broadcast information in real time and to mobilize people have also disseminated fear among governments. This results to restrictions on the ICT and freedom of expression is exposed to multi-faceted risks such as: censorship across large populations or networks, content filtering and blocking, identifications of activists and critics, disconnections of the technology access, leakage of user information are some of the challenges that can influence freedom of expression and the criminalization of legal expression followed by the adoption of restrictive legislation to rationalize such measures represent the disastrous culmination, use as well as outcome of these practices. 
The nature of the belief of innocence is controversial, as it expresses an essential contradiction [8]. Since this right is intended to ensure protection to those people who are suspected of having violated a criminal rule, the presumption of innocence can only work as guarantee for those people who are presumed to be guilty. Beitz (2011) [9] argues that the conceptualization of human rights to their political role and social role is perceived as a legal establishment for justifying and specifying the content of the human rights concept. "The right to receive the personal data concerning him or her, which he or she has provided to a controller, in a structured, commonly used and machine-readable format and have the right to transmit those data to another controller without hindrance from the controller to which the personal data have been provided" [10]. Chapman (2009) [11] suggested that to apply the preventive principle to the development of innovative technologies in such a way as to defend populations from the unsafe impacts of science and technology.

Internet is nowadays a basic requirement of modern society. The primary step towards understanding the internet architecture is to understand that it feeds on plentiful information being routed around its nodes. The modality of expression on website is based on two-way communication, making the end-user not only a passive recipient of information but also an active publisher. The Web architecture is vital for knowledge-based economy as it enhances competitiveness and innovation, promoting development and social enclosure. It strengthens democracy and affects human rights, by enhancing freedom of expression.

As mentioned by the United Nations [12], access to the Internet provides two parallel dimensions. One component is the access to online content, without any restrictions except in a limited cases provided under international human rights law. The second factor is the accessibility of the infrastructure and ICTs, such as cables, modems, computers and software to access the Internet. Even when Internet access is already guaranteed, new and controversial issues appear. The main concern deals with the risk of limitations that characterizes the free exercise of human rights. As one of the frequently happening social changes, Internet brings with it unexplored concerns and values which the international legal framework is unavoidably asked to address. Mass media is regarded as a powerful phenomenon, according to Graber and Dunaway (2017) [13] but any power cannot be complete, it must be controlled else it becomes precarious. The most recent developments in the present field seem to confirm the international customary law is ready to accept those rules which identify access to the Web as a human right.

\section{Social Networking Sites and Human Rights}

The social networking and its use for social and political movement can be observed in revolution in Egypt. The social networking and web tools were efficiently used by the activist and leader to channelize the strength and voice against their freedom of speech and political activity. New movements such as the partnership on Artificial Intelligence (AI) and Ethics and Governance of AI fund has been introduced, and several reports have been published on how to incorporate ethics, fairness, and human rights into machine learning and algorithmic decision making [4]. Digital innovations have exposed individuals' human rights to the risk of being critically humiliated and led to the appearance of a new necessity to explore new ways for the safeguard of human dignity either creating new rights or determining a change of perspective in the interpretation of traditional rights and its major issues. Problems arising from the security of information transfer when working in computer networks can be defined as Interception of information and Modification of information Lloyd [14].

Wael Ghonim, a Google Executive, set up his Facebook page and racked up nearly 400,000 followers and is credited for starting the Egyptian Youth revolution in 2011. Wael Ghonim is a computer engineer, an Internet activist, and a social entrepreneur. He believes that the Internet can be the most dominant platform for connecting Humanity, if we can bring civility and thoughtful conversations. Internet provides platform like Facebook and twitter which gives an opportunity to channelize the democratic movement for freedom of speech and Human rights.

In Kenya, people were able to aware authorities on electoral discrepancies and problems, for example, threats, vote purchase and violence by SMS during Kenya's 2010 Constitutional Referendum. In the Democratic Republic of Congo, a voice-based communication system called FreedomFone facilitated women to access pre-recorded information regarding sexual assaults such as their legal rights and health with a function to request call back. A coalition of organizations was able to enforce the law that requires the government to allot $4 \%$ of its GDP to education through a website with links to social media sites that provided facilities to post comments and show support. The Green Movement in Iran and the Arab are some of the examples.

Bauman (2012) [15] argues posing a lot of examples on social media's democratic advancement. Similar example can be taken in Libiya. Freedom House (2012) [16] stated as, "Welcome back to the Internet Libya," The Washington Post (blog), mentioned Qadhafi's regime employed a broad range of tactics for suppressing freedom of expression online, including maintaining monopoly control over the internet infrastructure, blocking websites, engaging in observation, and meting out punishments to online critics. Such restrictions intensified as the insurgency against Qadhafi's rule gained momentum in February 2011, culminating in an internet shutdown until the liberation of Tripoli in August 2011. 
Twitter is being used in many creative ways during major events, an example being the use of Twitter to break news during the American military attack that killed Al Qaeda leader Osama Bin Laden [17]. Twitter continues to form a significant tool for real time conversations around the world. The Commission could make use of Twitter for generating positive public opinion and content that generates positive comments and high traffic could be re-tweeted so as to get a wide publicity and popularity.

\subsection{YouTube and Webinars}

A series of webinars could be recorded live and uploaded to a YouTube and moderated by a leading expert in the field of human rights. Such an expert could be a former Commissioner, leading academic, or any other leading personality. Issues that the webinar could discuss could be many depending on the existing situations.

\subsection{Blogs}

Expert opinions complemented by first-hand accounts make for interesting and timely blogs. As there are quite a number of human rights experts on the continent who are quite good at global communications, the Commission considers soliciting for the services of expertise who could be asked to post blogs on frequent basis, and thereafter comments with illustrative examples of the issues under discussion would be entertained.

\section{Promoting Human Rights using IT}

Promotional activities of human rights include activities of gathering and disseminating information through workshops, seminars and symposia as well as the formulation of principles to address legal problems of human rights and co-operation with international human rights institutions. It also includes the gathering and propagation of documentation and information and the development of a global network of partner institutions. Promotional activities take a number of forms and can be fulfilled using different tools which can be organized at all levels by the Commission on its own or along with partners be it governments, government institutions or civil society organizations. These tools can be used to target people of all level of society. Other promotional activities involve translation, publication and dissemination of the information, promotion through the production and dissemination of the activities of the Commission and other information materials, and promotion through research and education. The volume of the task, coupled with the lack of time and resources has meant that many of these activities have had very limited impact. The persistence on promotion of human rights is based on the premise that if people are not aware of their rights, they cannot ensure their protection. The possible implication of actors other than the dictator in digital threats to citizens is lacking. It also suffers from a kind of repetitive reasoning: having once defined authoritarian regimes as those states that fail to organize free and fair elections, political actors beyond those states. This definition of the field blinds it to the possibility of authoritarian practices outside the purview of authoritarian regimes [18].

ICTs tools such as personal websites, blogs and discussion groups have provided a voice to people who were only passive consumers of information. The bottom-line is therefore is to sound an alarm and to alert to the attempts by various national governments to dowse the people's voice through ICTs and via arbitrary actions which resort to blocking ICT outlets whenever people seek to exercise their offline as well as online rights. It can be argued, as Costea (2007) [19] mention that "the Internet and the world wide web has reached the point when nobody can afford to ignore it, at their own loss." As one of the key forces determining economic growth, a globalized world needs to use ICT to unlock the untapped potential to improve people's living conditions. Burt (2010) [20] highlights how ICT can easily guide in many technological breakthroughs but at the same time could cause disasters if not handled expeditiously.

ICTs have shown to intensify people's voices, usually the disadvantaged in society and a voice that enables the poor and those with disabilities to use their knowledge to avoid poverty. The use of ICTs and the Internet can help to promote human rights. As the Special Rapporteur opined in his report, the unique and transformative nature of the Internet and by extension of ICTs can assist promote the progress of society. Human rights education, training and public information have been mentioned as basic components for the promotion of human rights and achievement of stable and harmonious relations in communities. ICTs are not the ultimate solution by themselves, their effective usage facilitates people to become self-sufficient in meeting their basic requirements in everyday life and reach their full potential.

There is limited value in analyzing the relationships between ICTs and human rights if the key topics of democracy and good governance are not addressed. One can help to proliferate the other, both must be contextualized as the byproducts of the same system. The main impact of ICTs on democratic system concerns capability to strengthen the public sphere by increasing the information resources, channels of electronic communication, and the networking capacity for interest groups, social movements, NGOs, transnational policy networks, and political parties with the technical know-how and organizational flexibility to adjust to the new medium [21]. Rights-based approaches to children's digital media practices are gaining focus as a framework for research, policy as well as initiatives that can balance children's need for protection online to maximize the opportunities and benefits of connectivity [22]. 


\section{Threats and Opportunities Arising from New Technology}

It is needed to fix priorities for response and so it is vital to understand which forms of technology instantly engage human rights. The World Economic Forum highlighted twelve types of technology that merit close attention. As technologies continuously develop and increase, these twelve technologies create new categories, processes, products and services as well as new value chains and organizational structures. They are:

- New computing technologies;

- Blockchain and distributed ledger technologies;

- The Internet of Things (IoT);

- $\mathrm{AI}$ and robotics;

- Advanced materials;

- Additive manufacturing and multidimensional printing;

- Biotechnologies;

- Neurotechnologies;

- Virtual reality and augmented reality;

- Energy capture, storage and transmission;

- Geoengineering;

- Space technologies.

\section{Conclusion}

ICTs have been playing a crucial role in establishing awareness and preventing violations of human rights across the globe. Electronic media has been playing a significant role against violation of human rights. International human rights organizations have proved effective for raising awareness and preventing violations of human rights. Digital literacy and effective use of ICT for human rights in a modern age need to be equipped for all sectors of society. More emphasis should be given to young people and to awareness and marginalized groups for prevention of human rights violations against them. As technologies have frequently changed through the years, their effects on individual life and society depend on how they will be shaped under many factors' influences, among which a major role will be played by a country's law.

\section{Declaration of Competing Interest}

The authors declare that they have no known competing financial interests or personal relationships that could have appeared to influence the work reported in this paper.

\section{References}

[1] Technology and Human Rights. (2019). The social and cultural implications of information \& communication technology (ICT) on human rights, humanitarian action, and social change. Available online: technologyandhumanrights.org (accessed on May 2019).

[2] Eliot, N. (2010). The use of ICT in Human Rights promotion: A case study of the African Commission on Human and Peoples' Rights. Available online: http://www.diplomacy.edu/sites/default/files/IGCBP2010_2011_Nsega.pdf. (accessed on May 2019).

[3] United Nations, (2012c). Human Rights Council Resolution 20/8, Promotion and protection of all human rights, civil, political, economic, social and cultural rights, including the right to development, A/HRC/RES/20/8 (16 July 2012). Available online: https://documents-dds-ny.un.org/doc/resolution/gen/G12/153/25/pdf/G1215325.pdf?OpenElement (accessed on January 2017).

[4] United Nations, Office of the High Commissioner on Human Rights. (2019). Concept Note for the United Nations Forum on Business and Human Rights, Geneva, 25-27 November 2019. Available online: https://www.businesshumanrights.org/en/ eighth-annual-forum-on-business-and-human-rights-geneva-25-27-nov-2019 (accessed on October 2019).

[5] Kerikmäe, T., Hoffmann, T., \& Chochia, A. (2018). Legal Technology for Law Firms: Determining Roadmaps for Innovation. Croatian International Relations Review, 24(81), 91-112. doi:10.2478/cirr-2018-0005.

[6] Karanasiou, A. P. (2012) 'Respecting Context: A New Deal for Free Speech in the Digital Era', European Journal of Law and Technology, Corpus ID: 9958570, 3(3), 1-38. 
[7] Bertot, J. C., Jaeger, P. T., \& Grimes, J. M. (2010). Using ICTs to create a culture of transparency: E-government and social media as openness and anti-corruption tools for societies. Government Information Quarterly, 27(3), $264-271$. doi:10.1016/j.giq.2010.03.001.

[8] Jong, F. de, \& Lent, L. van. (2016). The Presumption of Innocence as a Counterfactual Principle. Utrecht Law Review, 12(1), 32. doi:10.18352/ulr.324.

[9] Beitz, C. R. (2011). The idea of human rights. Oxford University Press, Oxford, United Kingdom. doi:10.1093/acprof:oso/9780199572458.001.0001.

[10] European Union. (2016). European Parliament and Council Regulation 2016/679/EU, The protection of natural persons with regard to the processing of personal data and on the free movement of such data, and repealing Directive 95/46/EC (General Data Protection Regulation), 2016 O. J. L 119.

[11] Chapman, A. R. (2009). Towards an Understanding of the Right to Enjoy the Benefits of Scientific Progress and Its Applications. Journal of Human Rights, 8(1), 1-36. doi:10.1080/14754830802701200.

[12] United Nations, (2011a) Human Right Council, Report of the Special Rapporteur on the promotion and protection of the right to freedom of opinion and expression, A/HRC/17/27, (May 2011). Available online: http://www2.ohchr.org/english/bodies/ hrcouncil/docs/ 17session/A. HRC.17.27_en.pdf (accessed on 3 January 2017).

[13] Graber, D. A., \& Dunaway, J. (2017). Mass media and American politics. CQ Press, Washington, D.C., United States.

[14] Lloyd, I. (2017). Information technology law. Oxford University Press, Oxford, United Kingdom.

[15] Bauman, Z. (2012). Collateral Damage: social inequalities in a global age. Cambridge; Malden: Polity Press. $15(2), 235$. doi:10.3917/mana.152.0235.

[16] Freedom House. (2012). Freedom on the Net 2012. Washington, D.C., United States. Available online: https://freedomhouse.org/sites/default/files/Libya\%202012.pdf (accessed on October 2019).

[17] Mashable Inc. (2011). One Twitter User Reports Live from Osama Bin Laden Raid. Available online: http://mashable.com/2011/05/01/live-tweet-bin-laden-raid/ (accessed on December 2019).

[18] Glasius, M. (2018). What authoritarianism is, and is not: a practice perspective. International Affairs, 94(3), 515-533. doi:10.1093/ia/iiy060.

[19] Costea, D.R. (2007). Multilateralism: fading or changing? In Foreign ministries: managing diplomatic networks and optimizing value (Eds: Rana, K., Kurbalija, J.). Malta, Msida, DiploFoundation, Belgrade, Serbia.

[20] Burt, A. (2010). Effects on Diplomacy of Internet Technologies. Proceedings of a Westminster Hall Debate, December 2010. Available online: http://www.fco.gov.uk/en/news/latest-news/?view=Speech\&id=477426682. (accessed on May 2019).

[21] Norris, P., (2002). "E-Voting as the Magic Ballot? The impact of Internet voting on turnout in European Parliamentary elections", Paper for the Workshop on "E-voting and the European Parliamentary Elections", Robert Schuman Center for Advanced Studies, Villa La Fonte, EUI. Available online: http://ksghome.harvard.edu/ .pnorris.shorenstein.ksg/ACROBAT/ agic\%20Ballot.pdf (accessed on October 2019).

[22] Livingstone, S., \& Third, A. (2017). Children and young people's rights in the digital age: An emerging agenda. New Media \& Society, 19(5), 657-670. doi:10.1177/1461444816686318. 